\title{
Cyclobutene vs 1,3-Diene Formation in the Gold-Catalyzed Reaction of Alkynes with Alkenes: The Complete Mechanistic Picture
}

M. Elena de Orbe, ${ }^{\dagger}$ Laura Amenós, ${ }^{\dagger}$ Mariia S. Kirillova, ${ }^{\dagger}$ Yahui Wang, ${ }^{\dagger}{ }^{\dagger}$ Verónica López-Carrillo, ${ }^{\dagger}$ Feliu Maseras, $,^{*}, * \oplus$ and Antonio M. Echavarren ${ }^{*}, t, \$ \odot$

\footnotetext{
${ }^{\dagger}$ Institute of Chemical Research of Catalonia (ICIQ), The Barcelona Institute of Science and Technology, Av. Països Catalans 16, 43007 Tarragona, Spain

${ }^{\ddagger}$ Departament de Química, Universitat Autònoma de Barcelona, 08193 Bellaterra, Spain

${ }^{\S}$ Departament de Química Analítica i Química Orgànica, Universitat Rovira i Virgili, C/Marcel·li Domingo s/n, 43007 Tarragona, Spain
}

Supporting Information

ABSTRACT: The intermolecular gold(I)-catalyzed reaction between arylalkynes and alkenes leads to cyclobutenes by a $[2+$ 2] cycloaddition, which takes place stepwise, first by formation of cyclopropyl gold(I) carbenes, followed by a ring expansion. However, 1,3-butadienes are also formed in the case of orthosubstituted arylalkynes by a metathesis-type process. The corresponding reaction of alkenes with aryl-1,3-butadiynes, ethynylogous to arylalkynes, leads exclusively to cyclobutenes. A comprehensive mechanism for the gold(I)-catalyzed reaction of alkynes with alkenes is proposed on the basis of density functional theory calculations, which shows that the two pathways leading to cyclobutenes or dienes are very close in energy. The key intermediates are cyclopropyl gold(I) carbenes, which have been independently generated by retro-Buchner reaction from stereodefined 1a,7b-dihydro- $1 H$-cyclopropa $[a]$ naphthalenes.

\section{INTRODUCTION}

Cycloisomerizations of $1, n$-enynes catalyzed by gold(I) and other electrophilic metals proceed by mechanistically complex, multistep transformations that lead to novel architectures ${ }^{1}$ and have been applied for the total synthesis of a variety of natural products. $^{2}$ The parent intermolecular reaction between terminal alkynes $\mathbf{1}$ and alkenes $\mathbf{2}$ gives rise to cyclobutenes $\mathbf{3}$ as a result of a $[2+2]$ intermolecular cycloaddition (Scheme 1). Key for the success of this reaction was the use of cationic gold(I) complex A with a very bulky phosphine. By exchanging the anion of catalyst $\mathrm{A}$ from $\mathrm{SbF}_{6}^{-}$to softer $\mathrm{BAr}_{4}{ }^{\mathrm{F}-}$, cyclobutenes 3 were obtained in better yields presumably by decreasing the rate of formation of $\sigma, \pi$-digold(I) alkyne complexes, which were shown to be unproductive dead ends in this transformation. ${ }^{4}$ We have extended this $[2+2]$ cycloaddition for the synthesis of up to 15 -membered ring macrocycles by performing the reaction with $1, n$-enynes $(n=$ $10-16),{ }^{5}$ which has been applied for the enantioselective total synthesis of rumphellaone A. ${ }^{6}$

Cyclobutenes are highly valuable synthons for the preparation of functionalized cyclobutanes and other compounds. ${ }^{7,8}$ Besides photochemical processes, ${ }^{9}$ other transition metals different from gold(I) have been used to promote $[2+2]$ cycloaddition reactions, which are however rather limited with respect to the range of alkenes that can be used. ${ }^{10,11}$ Thus, the rhodium-catalyzed $[2+2]$ cycloaddition only proceeds with

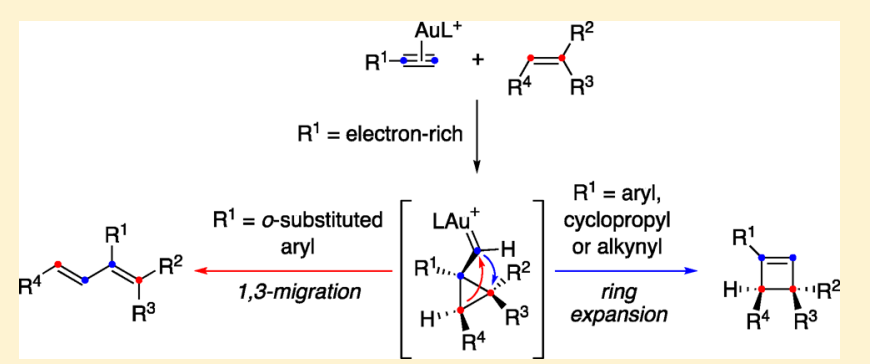

Scheme 1. Gold(I)-Catalyzed [2 + 2] Cycloaddition of Alkynes with Alkenes ${ }^{3,4}$ or Formation of 1,3-Dienes and Lactones $^{20}$

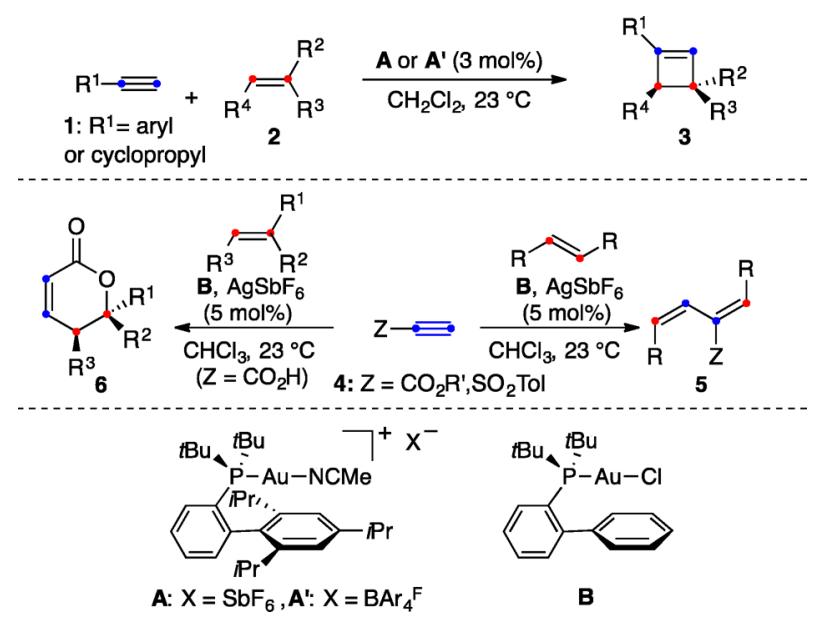

electron-deficient ${ }^{12,13}$ or strained alkenes. ${ }^{14}$ Other transitionmetal catalysts also promote the $[2+2]$ cycloaddition of strained alkenes with alkynes. ${ }^{15,16}$ The reaction of propiolates

Received: March 26, 2017

Published: July 12, 2017 
and other alkynes bearing electron-withdrawing groups with alkenes in the presence of Lewis ${ }^{17}$ or Brønsted ${ }^{18}$ acids also leads to cyclobutenes. ${ }^{19}$ Interestingly, in the presence of gold(I), this type of alkyne reacts with alkenes to form 1,3dienes 5 or lactones 6 (Scheme 1$).^{20}$

On the basis of studies on the mechanism of gold(I)catalyzed cyclization of $1, n$-enynes ${ }^{21-24}$ and other electrophiles, ${ }^{25,26}$ we hypothesized that the reaction of alkynes with alkenes could take place by the electrophilic addition of $\left(\eta^{2}\right.$ alkyne)gold(I) complexes 7 to the alkene to form intermediate cyclopropyl gold(I) carbenes 8, which undergo ring expansion to give $\left(\eta^{2}\right.$-cyclobutene) gold(I) complexes 9 (Scheme 2$)$. An intermediate $\left(\eta^{2}\right.$-cyclobutene)gold(I) complex has been spectroscopically detected at low temperature from a 1,6enyne. $^{27}$

Scheme 2. Mechanistic Hypothesis for the $[2+2]$

Cycloaddition of Electron-Rich Alkynes ${ }^{3,4}$ vs Formation of 1,3-Dienes or Lactones from Electron-Deficient Alkynes ${ }^{20}$
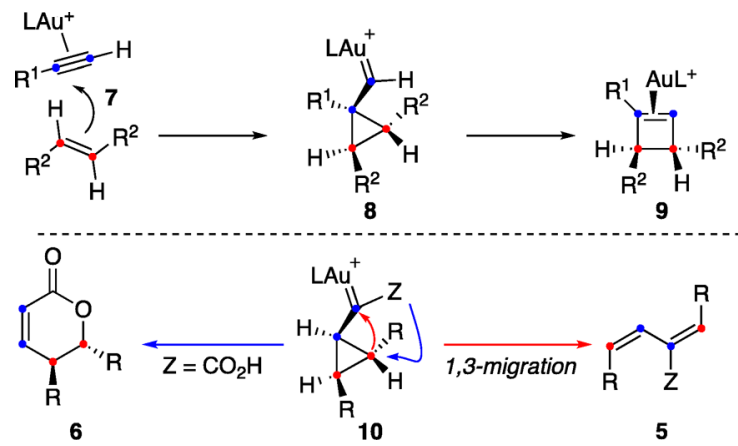

In the case of electron-rich alkynes, the alkene reacts by attack at the internal carbon, ${ }^{3,4}$ whereas electron-deficient alkynes react at the terminal carbon, leading to intermediates 10, which can undergo formal 1,3-migration to give 1,3-dienes $\mathbf{5}$ or experience intramolecular attack by the carboxylic acid ( $\mathrm{Z}$ $\left.=\mathrm{CO}_{2} \mathrm{H}\right)$ to afford 6 (Scheme 2$) .^{20}$

The very different outcomes of the reactions of electron-rich aryl- or cyclopropyl-substituted alkynes and alkynes bearing electron-withdrawing groups are rather striking. Therefore, we decided to examine in detail the reaction of a broader range of terminal alkynes to get a clearer perspective of this fundamental reaction in gold(I) chemistry. Surprisingly, we found that some ortho-substituted arylalkynes react with alkenes to give 1,3dienes in a metathesis-type process. On the other hand, less sterically demanding 1,3-butadiynes lead exclusively to cyclobutenes. Here we report these results along with a detailed theoretical analysis of the mechanism of formation of cyclobutenes or 1,3-dienes. To support the initial involvement of cyclopropyl gold(I) carbenes in these transformations, we also studied the generation of these intermediates by a retroBuchner reaction. This study leads to a comprehensive picture of the gold(I)-catalyzed reactions of alkynes with alkenes.

\section{RESULTS AND DISCUSSION}

Formation of Cyclobutenes vs 1,3-Dienes. The gold(I)catalyzed intermolecular reaction of substituted arylalkynes with alkenes affords cyclobutenes 3 in moderate to excellent yields. ${ }^{3,4}$ Thus, under the optimized conditions, reaction of phenylacetylene with $\alpha$-methylstyrene (2a) gives rise to cyclobutene $3 a$ in $95 \%$ yield (Table 1 , entry 1 ). ${ }^{28}$ However,
Table 1. Cycloaddition vs Rearrangement in the Reaction of Alkynes $1 \mathrm{a}-\mathrm{j}$ with Alkenes $2 \mathrm{a}-\mathrm{e}^{a, 31}$

\begin{tabular}{|c|c|c|c|c|}
\hline \multicolumn{2}{|c|}{$\begin{array}{l}\quad \mathrm{R}^{1-}= \\
\text { 1a: } \mathrm{R}^{1}=\mathrm{Ph} \\
\text { 1b: } \mathrm{R}^{1}=0-\mathrm{MeC}_{6} \mathrm{H}_{4} \\
\text { 1c: } \mathrm{R}^{1}=0-\mathrm{FC}_{6} \mathrm{H}_{4} \\
\text { 1d: } \mathrm{R}^{1}=0-\mathrm{ClC}_{6} \mathrm{H}_{4} \\
\text { 1e: } \mathrm{R}^{1}=0-\mathrm{BrC}_{6} \mathrm{H}_{4} \\
\text { 1f: } \mathrm{R}^{1}=0-\mathrm{MeOC}_{6} \mathrm{H}_{4} \\
\text { 1g: } R^{1}=0-\mathrm{CF}_{3} \mathrm{C}_{6} \mathrm{H}_{4} \\
\text { 1h: } \mathrm{R}^{1}=p-\mathrm{CF}_{3} \mathrm{C}_{6} \mathrm{H}_{4} \\
\text { 1i: } \mathrm{R}^{1}=1-\mathrm{Naphthyl} \\
\text { 1j: } \mathrm{R}^{1}=9-\text { - Phenanthryl }\end{array}$} & \multicolumn{2}{|c|}{$\begin{array}{l}R_{R^{4}}^{R^{2}} \\
\text { 2a: } R^{2}=M e, R^{3}=P h, R^{4}=H \\
\text { 2b: } R^{2}-R^{3}=-\left(\mathrm{CH}_{2}\right)_{5}-, R^{4}=H \\
\text { 2c: } R^{2}-R^{3}=-\left(\mathrm{CH}_{2}\right)_{4}, R^{\circ}=H \\
\text { 2d: } R^{2}=R^{3}=M e, R^{4}=E t \\
\text { 2e: } R^{2}=H, R^{3}-R^{4}=-\left(\mathrm{CH}_{2}\right)_{6}^{-}\end{array}$} & $\underbrace{\mathrm{R}^{3}}_{11 \mathrm{a}-\mathrm{t}}$ \\
\hline entry & 1 & 2 & $3{\text { (yield, } \%)^{b}}^{b}$ & $11{\text { (yield, } \%)^{b}}^{b}$ \\
\hline 1 & 1a & $2 a$ & 3a $(95)^{c}$ & \\
\hline $2^{d, e}$ & $1 b$ & $2 a$ & $3 b(37)$ & $11 \mathbf{b}(29)$ \\
\hline 3 & $1 c$ & $2 a$ & $3 c(64)$ & $11 c(3)$ \\
\hline $4^{e-g}$ & $1 d$ & $2 a$ & $3 d(9)$ & 11d (48) \\
\hline $5^{f}$ & le & $2 a$ & $3 \mathbf{e}\left(3,3^{i}\right)$ & 11e $\left(45,43^{i}\right)$ \\
\hline 6 & If & $2 a$ & $3 f(54,54)$ & \\
\hline 7 & $1 \mathrm{~g}$ & $2 a$ & & $11 g(36)$ \\
\hline $8^{e, h}$ & $1 \mathrm{~h}$ & $2 a$ & $3 \mathrm{~h}(75)$ & $11 \mathrm{~h}(5)$ \\
\hline 9 & $1 b$ & $2 b$ & $3 \mathbf{i}(65)$ & $11 \mathbf{i}(27)$ \\
\hline 10 & $1 \mathrm{c}$ & $2 b$ & $3 \mathbf{j}\left(50,49^{i}\right)$ & $\mathbf{1} \mathbf{1 j}\left(25,20^{i}\right)$ \\
\hline 11 & 1d & $2 b$ & $3 \mathbf{k}(54,49)$ & $11 \mathbf{k}(33,28)$ \\
\hline 12 & $1 e$ & $2 b$ & $31(44)$ & $111(25)$ \\
\hline 13 & If & $2 b$ & $3 \mathrm{~m}(50)$ & $11 \mathrm{~m}(3)$ \\
\hline 14 & $1 \mathrm{i}$ & $2 b$ & $3 n(40)$ & $\ln (22)$ \\
\hline 15 & $1 \mathrm{j}$ & $2 b$ & 3o (48) & $110(19)$ \\
\hline 16 & $1 b$ & $2 c$ & $3 p(61)$ & $11 p(38)$ \\
\hline 17 & 1c & $2 c$ & $3 q(51,44)$ & $\mathbf{1 1} \mathbf{q}(33,17)$ \\
\hline 18 & $1 d$ & $2 c$ & $3 \mathbf{r}(25)$ & $11 \mathbf{r}(43)$ \\
\hline 19 & 1e & $2 c$ & $3 s(24)$ & 11s (42) \\
\hline 20 & If & $2 c$ & $3 \mathbf{t}(58,53)$ & $11 \mathbf{t}(24,12)$ \\
\hline 21 & le & $2 d$ & $3 \mathbf{u}\left(40,41^{j}\right)$ & $\mathbf{1} \mathbf{u}(34,37)$ \\
\hline 22 & 1e & $2 e$ & $3 \mathbf{v}(84)$ & $11 \mathbf{v}(5)$ \\
\hline
\end{tabular}

${ }^{a}$ Alkyne:alkene in a $1: 2$ ratio. ${ }^{b}$ Yields determined by ${ }^{1} \mathrm{H}$ NMR using 1,4-diacetylbenzene as the internal standard. Selected isolated yields in italics. See the Supporting Information for the other isolated yields. ${ }^{c}$ Reaction with $\mathbf{A}^{\prime}(3 \mathrm{~mol} \%)$ at $23^{\circ} \mathrm{C}^{4}{ }^{d}$ Alkyne:alkene in a 1:4 ratio. ${ }^{e} \mathrm{~A} 4 \mathrm{~mol} \%$ concentration of $\mathbf{A}^{\prime}$. ${ }^{f}$ Catalyst $\mathbf{A}$ instead of $\mathbf{A}^{\prime}$.

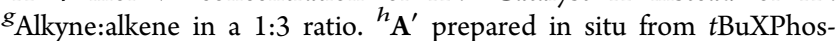
$\mathrm{AuCl}$ and $\mathrm{NaBAr}_{4}{ }^{\mathrm{F}} \cdot{ }^{i}$ Reaction on a $1 \mathrm{~g}$ scale of the alkyne. ${ }^{j}$ Mixture of 1,3,4,4- and 1,3,3,4-tetrasubstituted cyclobutenes in a 2.4:1 ratio.

the reaction of $o$-tolylacetylene $(\mathbf{1 b})$ with $\mathbf{2 a}$ in the presence of gold(I) complex $\mathbf{A}^{\prime}$ led to cyclobutene $3 \mathbf{b}$ together with 1,3diene $\mathbf{1 1 b}$ in a 1.3:1 ratio in moderate yields (Table 1 , entry 2 ). The reaction of ( $o$-fluorophenyl)acetylene (1c) with 2 a gave cyclobutene $3 \mathrm{c}$ in good yield together with traces of 1,3-diene 11c (Table 1, entry 3 ). In contrast, dienes $11 \mathbf{d}, \mathbf{e}$ were obtained as the major products in the reactions of (o-chlorophenyl)- and (o-bromophenyl)acetylenes (1d,e) with 2a (Table 1, entries 4 and 5). ${ }^{29}$ Interestingly, $o$-anisylacetylene (1f) gave exclusively cyclobutene $3 \mathrm{f}$ (Table 1 , entry 6$){ }^{30}$ whereas arylalkyne $\mathbf{1 g}$ with an $o-\mathrm{CF}_{3}$ group only afforded 1,3 -diene $\mathbf{1 1 g}$ (Table 1 , entry 7 ). However, moving the $\mathrm{CF}_{3}$ to the para position in $\mathbf{1 h}$ restored the usual reactivity, resulting in the formation of cyclobutene $3 \mathbf{h}$ as the major product (Table 1 , entry 8 ). Reactions with methylenecyclohexane (2b) or methylenecyclopentane (2c) led to mixtures of cyclobutenes 3 and 1,3-dienes 11 (Table 1 , entries 9-20), although, in the reaction between $o$ anisylacetylene (1f) and $\mathbf{2 b}$, cyclobutene $3 \mathrm{~m}$ was obtained as 
the major product (Table 1, entry 13). 1-Naphthylacetylene (1i) and 9-phenanthrylacetylene $(\mathbf{1 j})$ also react with $\mathbf{2 b}$ to give cyclobutenes 3n,o and 1,3-dienes $\mathbf{1 1 n}, \mathbf{o}$ (Table 1, entries 14 and 15). Reaction of 1 e with 2-methyl-2-pentene (2d) rendered a mixture of cyclobutene $3 \mathbf{u}$ and 1,3-diene $\mathbf{1 1} \mathbf{u}$ products (Table 1, entry 21), whereas, in the reaction of $1 \mathbf{e}$ with $(Z)$-cyclooctene $(\mathbf{2 e})$, cyclobutene $3 \mathbf{v}$ was obtained as the major product in good yield (Table 1 , entry 22). The structure of bicyclo[6.2.0] dec-9-ene $3 \mathbf{v}$ was confirmed by X-ray diffraction.

1,3-Dienes $\mathbf{1} \mathbf{1} \mathbf{b}-\mathbf{h}$ were obtained as single E-stereoisomers, which was determined by NOE experiments. This assignment was confirmed in the case of 11e (Table 1, entry 5) by X-ray diffraction of crystalline derivative 11w, obtained from 11e by Suzuki coupling with $p$-nitrophenylboronic acid (Scheme 3).

Scheme 3. Derivatization of 11e To Form 1,3-Diene 11w

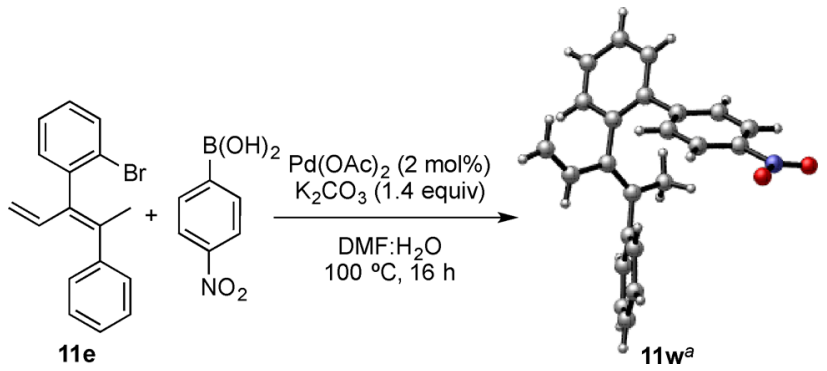

${ }^{a}$ CYLview depiction of the X-ray crystal structure of $11 w$.

Other metal catalysts known to promote cycloisomerization of $1, n$-enynes, such as $\mathrm{PtCl}_{2}, \mathrm{GaCl}_{3}$, and $\mathrm{InCl}_{3}$, fail to catalyze the reaction between alkyne 1a or 1e with $\alpha$-methylstyrene (2a) at 23 or $50{ }^{\circ} \mathrm{C}$. Similarly, neither cyclobutene nor 1,3diene was observed in the presence of $\mathrm{CuCl}, \mathrm{AgCl}, \mathrm{AgOTf}$, $\operatorname{AgNTf}_{2}, \mathrm{AgSbF}_{6}$, or $\left.\left[t \mathrm{BuXPhosAg}^{\mathrm{NCMe}}\right)\right] \mathrm{SbF}_{6}$ under these conditions.

Cyclobutenes from 1,3-Butadiynes. To delineate the importance of electronic and steric effects, we examined the gold(I)-catalyzed reaction of alkenes with aryl-1,3-butadiynes $12,{ }^{32}$ ethynylogous to arylalkynes 1 . Reaction of the parent 1 phenyl-1,3-butadiyne (12a) with 2,3-dimethylbut-2-ene (2f) led selectively to cyclobutene 13a by addition to the terminal triple bond with all the gold(I) catalysts tested (Table 2), although slightly better yields were obtained using NHCgold(I) complex F (Table 2, entry 6). ${ }^{33}$

Table 2. Gold(I)-Catalyzed Reaction of 1,3-Diyne 12a with Alkene $2 \mathrm{f}^{a}$

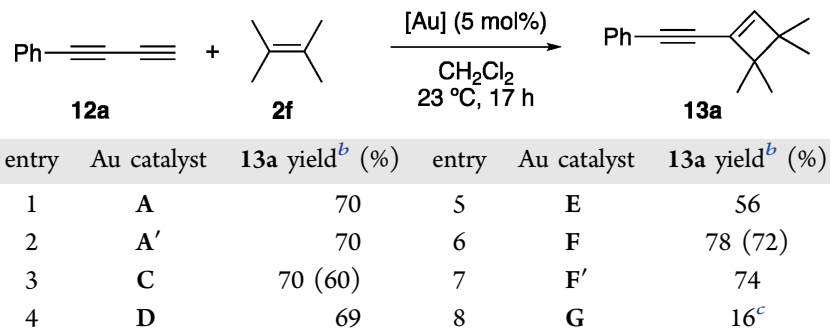

${ }^{a} 1,3$-Diyne:alkene in a $1: 2$ ratio. ${ }^{b}$ Yields determined by ${ }^{1} \mathrm{H}$ NMR using 1,4-diacetylbenzene as the internal standard. Isolated yields in parentheses. ${ }^{c}$ Conversion of $45 \%$.

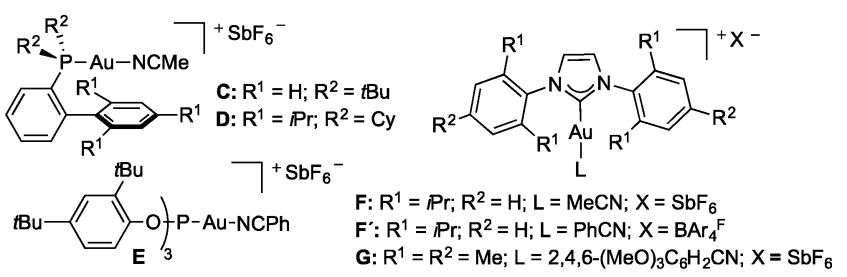

Differently substituted 1-aryl-1,3-diynes $\mathbf{1 2} \mathbf{a}-\mathbf{h}$ and 1thienyl-1,3-diyne (12i) react with alkene $2 \mathrm{f}$ to give 1ethynylcyclobutenes $13 \mathbf{a}-\mathbf{i}$ in good to excellent yields (Table 3). Alkyl-substituted 1,3-diyne $\mathbf{1 2} \mathbf{j}$ also leads to the

Table 3. Gold(I)-Catalyzed [2+2] Cycloaddition of 1,3Diynes $12 \mathrm{a}-\mathrm{j}$ with Alkenes $2 \mathrm{c}-\mathrm{j}^{a}$
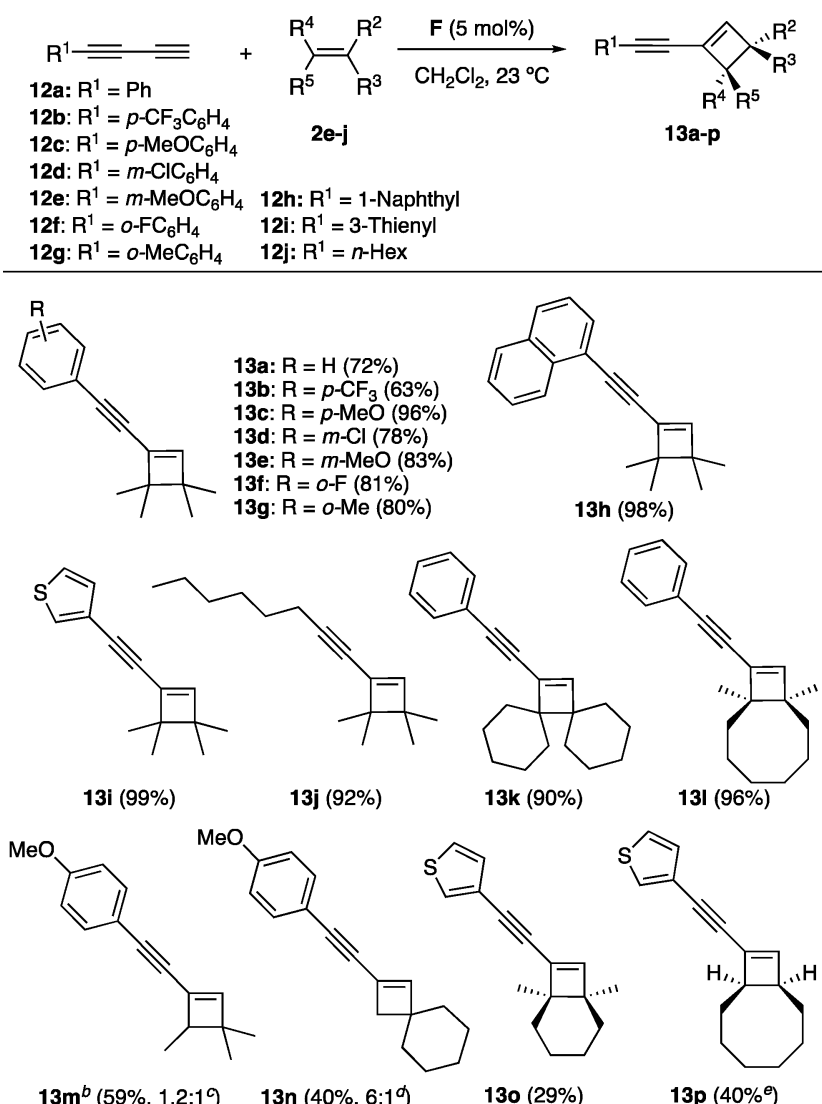

$13 m^{b}(59 \%, 1.2: 19) \quad 13 n\left(40 \%, 6: 1^{d}\right)$

$130(29 \%)$

$13 p\left(40 \%{ }^{e}\right)$

${ }^{a} 1,3$-Diyne:alkene in a 1:2 ratio. Isolated yields. ${ }^{b}$ Small amounts of $1,3-$ diene product were detected by ${ }^{1} \mathrm{H}$ NMR. ${ }^{c}$ The minor regioisomer is the 1,3,4,4-tetrasubstituted cyclobutene. ${ }^{d}$ The minor regioisomer is the 1,4,4-trisubstituted cyclobutene. Reaction at $40{ }^{\circ} \mathrm{C}$. ${ }^{e}$ Reaction at $50{ }^{\circ} \mathrm{C}$.

corresponding cyclobutene $\mathbf{1 3} \mathbf{j}$, which is remarkable, as alkynes with alkyl substituents are very poorly reactive with alkenes in the presence of gold(I) catalysts. ${ }^{3}$ Other di-, tri-, and tetrasubstituted alkenes $\mathbf{2 c - j}$ also reacted with 1,3-diynes 12a, 12c, and $2 \mathrm{i}$ to give 1 -alkynylcyclobutenes $13 \mathrm{k}-\mathrm{p}^{34}$

Mechanism of the Formation of Cyclobutenes or 1,3Dienes. To confirm the formal alkene fragmentation (metathesis-type) in the formation of 1,3-dienes in the intermolecular gold(I)-catalyzed reaction, a simple experiment between terminally deuterated alkyne $1 \mathbf{e}-d_{1}$ and alkene $\mathbf{2 a}$ with catalyst A was carried out (Scheme 4). In this reaction, we obtained exclusively 1,3-diene $11 \mathrm{e}-d_{1}$, revealing that a formal insertion of the alkyne into the alkene carbons takes place in this process. 
Scheme 4. Cycloaddition of Alkyne 1e- $d_{1}$ with 2 a

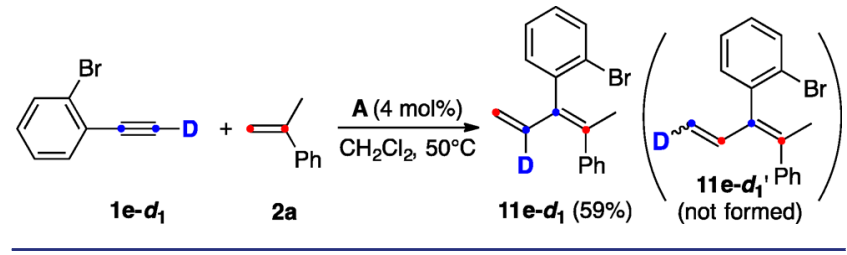

The alternative product, $11 \mathbf{e}-d_{1}{ }^{\prime}$, resulting from a doublecleavage-type rearrangement (formal cleavage of both the alkyne and the alkene; see below), was not observed.

Monitoring the reaction of alkyne $\mathbf{1 d}$ with alkene $\mathbf{2 b}$ (Table 1 , entry 11$)$ by ${ }^{1} \mathrm{H}$ NMR shows that the $[2+2]$ cycloaddition leading to cyclobutene $3 \mathrm{k}$ is ca. 1.4 times faster than the formation of 1,3-diene 11k (Scheme 5).

Scheme 5. Reaction of Alkyne 1d with Alkene $2 b^{a}$

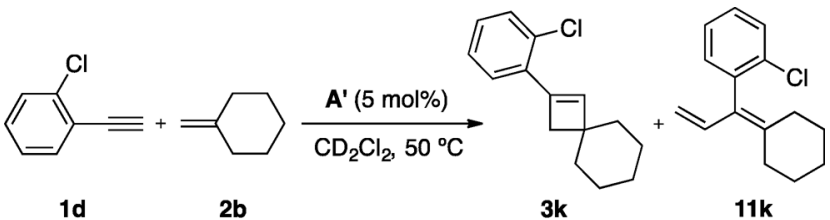

2b

3k

$11 \mathrm{k}$

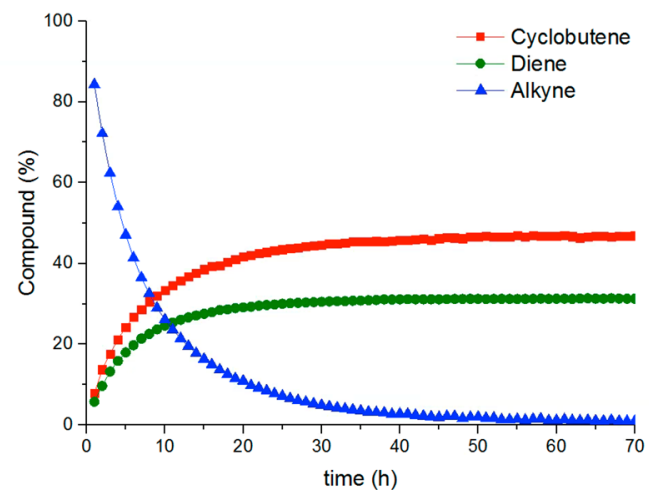

${ }^{a}$ Reaction progress followed by ${ }^{1} \mathrm{H} \mathrm{NMR}\left(\mathrm{Ph}_{2} \mathrm{CH}_{2}\right.$ internal standard).

For a deeper insight into the mechanism of the formation of cyclobutenes $\mathbf{3}$ and/or 1,3-dienes $\mathbf{1 1}$ as well as the influence of the substituents on the substrates in the reaction outcome, we performed density functional theory (DFT) calculations ${ }^{35}$ using $\mathrm{PMe}_{3}$ as the ligand for gold(I). ${ }^{36}$ We examined the reaction between phenylacetylene (1a) and $\alpha$-methylstyrene (2a) to give cyclobutene $3 \mathbf{a}$ as well as the reaction of (o-bromophenyl)acetylene (1e) with 2 a leading to 1,3 -diene $11 \mathrm{e}$ as the major product.

Electron-rich alkenes coordinate preferentially with gold(I), leading to $\left(\eta^{2}\right.$-alkene)gold(I) complexes that can be isolated and structurally characterized. ${ }^{37}$ Accordingly, the reaction begins with the associative ligand exchange of ( $\eta^{2}$-alkene)gold(I) complex Intla to generate the slightly less stable $\left(\eta^{2}\right.$ alkyne)gold(I) complex Int2a (Scheme 6). The attack of the alkene to the gold(I) alkyne complex Int2a can take place in an anti or a syn fashion to form intermediates Int4a and Int4b, which are in equilibrium due to $\mathrm{C} 3-\mathrm{C} 4$ bond rotation via ringopened intermediate Int4ab. ${ }^{38}$ In both cases, formation of intermediates Int4a,b with the gold(I) carbene at the terminal carbon is kinetically more favored than the formation of regioisomeric Int3a,b by at least $3.8 \mathrm{kcal} / \mathrm{mol}$. Although
Scheme 6. Ligand Substitution and Formation of Key Intermediates Int $4^{a}$

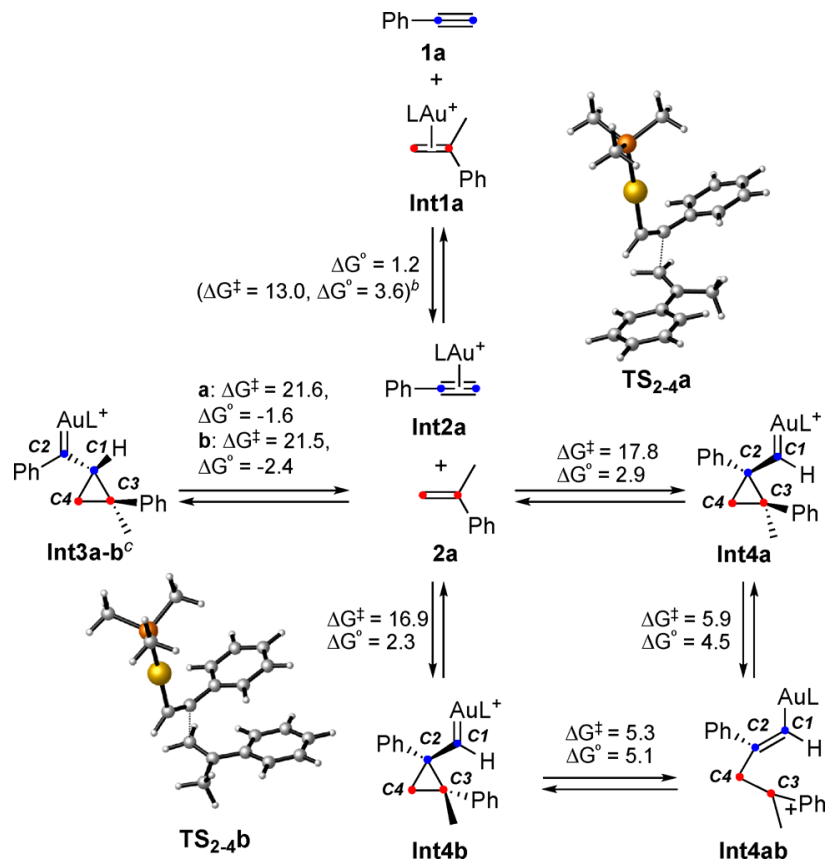

${ }^{a}$ Free energies in $\mathrm{kcal} / \mathrm{mol} . \mathrm{L}=\mathrm{PMe}_{3} .{ }^{b}$ Calculations using 2methylpropene instead of $\alpha$-methylstyrene. ${ }^{c}$ Depicted configuration of C3 for Int3a. Opposite configuration of C3 for Int3b.

formation of Int $4 \mathbf{b}$ requires $0.9 \mathrm{kcal} / \mathrm{mol}$ lower energy than Int4a, further evolution of Int4a to other intermediates proceeds through lower energy barriers. ${ }^{39}$

The possibility of an oxidative cyclometalation was also considered. ${ }^{40}$ However, neither the intermediate with the alkyne and the alkene coordinated simultaneously to gold(I) nor the gold(III) metalacyclopentene was found as a stable species.

Intermediate Int4a is also in equilibrium via $\mathrm{C} 4$ migration with the cyclopropyl-type intermediate Int5a, whose ring opening leads directly to (1,3-diene)gold(I) complex Int8a through $\mathbf{T S}_{5-8} \mathbf{a}\left(\Delta G^{\ddagger}=9.9 \mathrm{kcal} / \mathrm{mol}\right)$ (Scheme 7$)$. The alternative C3 migration would lead to a less stable cyclopropyl methyl intermediate to ultimately form a different type of 1,3diene that was not observed experimentally. The opening of the cyclopropane of Int5a via $\operatorname{TS}_{5-6} \mathbf{a}\left(\Delta G^{\ddagger}=10.7 \mathrm{kcal} / \mathrm{mol}\right)$ to form the less stable intermediate Int6a, followed by a highly exothermic 1,2-H shift, would give 1,3-diene-gold(I) complex Int9a. However, formation of either Int8a or Int9a from Int5a requires higher activation energies than the conversion of Int5a to Int4a $\left(\Delta G^{\ddagger}=5.7 \mathrm{kcal} / \mathrm{mol}\right)$. Comparing all the activation energies, the most favored reaction pathway is the ring expansion of Int4a to give $\left(\eta^{2}\right.$-cyclobutene)gold(I) complex Int7a $\left(\Delta G^{\ddagger}=8.9 \mathrm{kcal} / \mathrm{mol}\right)$. Conrotatory ring opening of Int7a to form Int10a is unlikely as it would have to overcome a prohibitively high energy barrier of $32.1 \mathrm{kcal} / \mathrm{mol}^{41}$ Thus, our calculations predict that cyclobutene 3 a would be the product of the reaction, which is consistent with the formation of $3 a$ in a 95\% yield from 1a and 2a (Table 1, entry 1).

The reaction of (o-bromophenyl)acetylene (1e) with $\alpha$ methylstyrene (2a) is more complex as four different approaches of the alkene toward the Int $4 \mathbf{c}-\mathbf{f}$ could be conceived (Scheme 8) depending on the relative orientation 
Scheme 7. Formation of Cyclobutene or 1,3-Dienes from Intermediate Int $4 a^{a}$

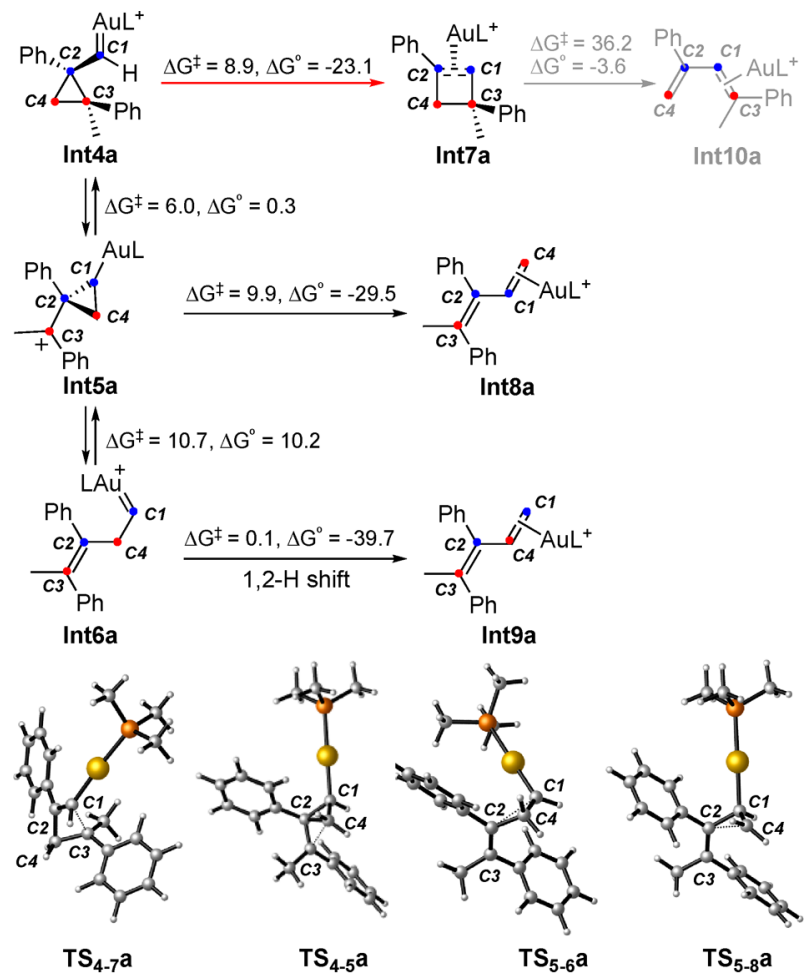

${ }^{a}$ Free energies in $\mathrm{kcal} / \mathrm{mol} . \mathrm{L}=\mathrm{PMe}_{3}$.

Scheme 8. Mechanism of the Reaction between 1e $(\mathrm{Ar}=\boldsymbol{o}$ Bromophenyl) and $2 \mathrm{a}^{a}$

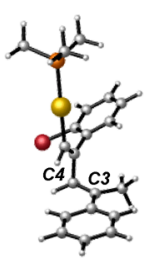

Int4c

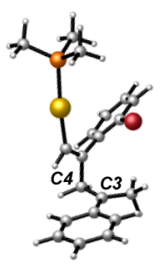

Int4d

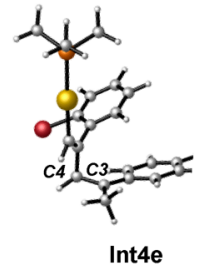

Int4e

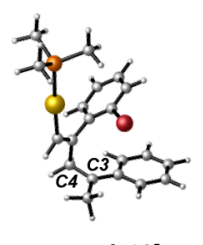

Int4f c: $\Delta G^{\ddagger}=11.9, \Delta G^{\circ}=-19.6$

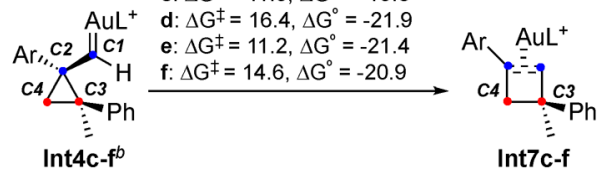

Int4c-f $f^{b}$ Int7c-f

c: $\Delta G^{\ddagger}=12.0, \Delta G^{\circ}=2.0$

d: $\Delta \mathrm{G}^{\ddagger}=6.4, \Delta \mathrm{G}^{\circ}=-0.2$

e: $\Delta G^{\ddagger}=14.3, \Delta G^{\circ}=-0.2$

f: $\Delta G^{\ddagger}=8.4, \Delta G^{\circ}=1.2$

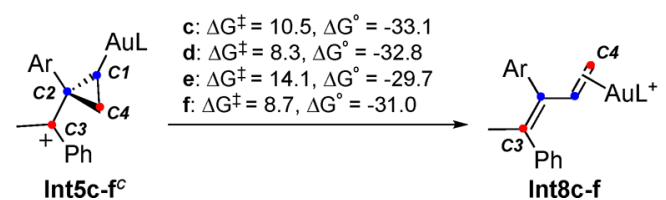

${ }^{a}$ Free energies in $\mathrm{kcal} / \mathrm{mol} . \mathrm{L}=\mathrm{PMe}_{3}$. Depicted configuration of $\mathrm{C} 3$ for pathways $\mathrm{c}$ and $\mathrm{d}$. Opposite configuration of $\mathrm{C} 3$ for pathways e and f. ${ }^{b}$ Transformations among Int $4 \mathbf{c}-\mathbf{f}$ via bond rotations: see the Supporting Information. ${ }^{c}$ Transformation of Int5f into Int5d via C2C3 bond rotation: $\Delta G^{\ddagger}=14.0 \mathrm{kcal} / \mathrm{mol}, \Delta G^{\circ}=-0.6 \mathrm{kcal} / \mathrm{mol}$. of the phenyl groups of the substrates (anti or syn) and the position of the ortho-substituent in the alkyne with respect to the olefin carbons (ortho-substituent closer to either the terminal or internal alkene carbon). Thus, four distinct reaction pathways were computed for this system (c-f, Scheme 8). As in the case of the reaction of phenylacetylene (1a) with alkene 2a, formation of the cyclopropyl gold(I) carbene at the internal alkyne carbon (Int $4 \mathrm{c}-\mathrm{f}, \Delta G^{\neq}=16.7-17.5 \mathrm{kcal} / \mathrm{mol}$ ) is more favorable than at the terminal alkyne carbon (Int3c-f, $\Delta G^{\ddagger}=$ $18.8-20.1 \mathrm{kcal} / \mathrm{mol}) .^{39}$ Comparison of the activation energies of the transformations of Int $4 c-f$ into Int $5 c-f$ or Int $7 c-f$ suggests that the $o$-bromo substituent hampers the rearrangement of the near alkene carbon and favors the rearrangement of the further alkene carbon. In fact, cyclopropyl gold(I) carbenes Int4d and Int4f bearing the bromo atom closer to C3 prefer to form intermediates Int5d and Int5f via rearrangement of $\mathrm{C} 4$, which then lead to 1,3-diene-gold(I) complexes Int8d and Int8f, respectively. In contrast, cyclopropyl gold(I) carbene Int4e bearing the $o$-bromo substituent closer to $\mathrm{C} 4$ prefers to undergo ring expansion through $\mathrm{C} 3$ to give the $\left(\eta^{2}\right.$ cyclobutene)gold(I) complex Int7e. Analyzing all the energy barriers (including bond rotations), the most favored pathway is that to 1,3-diene-gold(I) complex Int8d. This is in agreement with the experimental result, as 1,3-diene $11 \mathrm{e}$ is obtained in a $45 \%$ yield and only traces of cyclobutene $3 \mathbf{e}$ are detected (Table 1 , entry 5 ). Nevertheless, the difference in the activation energies of the rearrangements of cyclopropyl gold(I) carbenes Int4 are not large, so subtle changes in the substitution pattern of the substrates modify the steric interactions and, consequently, the reaction outcome. Then, reasonably, different ratios of cyclobutene and 1,3-diene products were experimentally obtained depending on the differently substituted substrates.

For the sake of completeness, the mechanism of the gold(I)catalyzed reaction between 1-phenyl-1,3-butadiyne (12a) and alkenes was also studied computationally (Scheme 9). Gold(I) complex Int $2 \mathbf{h}$, in which gold(I) is coordinated to the terminal alkyne, is $2.8 \mathrm{kcal} / \mathrm{mol}$ more stable than the complex Int $2 \mathrm{~g}$ with gold(I) coordinated to the internal alkyne. The preferential binding of gold(I) to the less substituted multiple bond has been experimentally observed in the case of allenes. ${ }^{43}$ (Alkyne)gold(I) complex Int2g shows an almost symmetrical $\eta^{2}$-coordination with a significant bending back of the phenyl group, which is consistent with reported structures of related (alkyne)gold(I) complexes. ${ }^{44}$ In contrast, in complex Int 2 h, the terminal alkyne binds very unsymmetrically with gold(I), resulting in longer bonds with the substituted carbon atom, as also observed in terminal (alkene)gold(I) complexes. ${ }^{37,45}$

The free energy of activation for the attack of the alkene on the terminal alkyne is $3.4 \mathrm{kcal} / \mathrm{mol}$ lower than the barrier corresponding to the attack at the internal alkyne (Scheme 9). Consequently, on both thermodynamic and kinetic grounds, the alkene selectively attacks complex Int $2 \mathbf{h}$ at the terminal alkyne as a $\pi$-nucleophile, forming distorted cyclopropyl gold(I) carbene Int4h. The ring expansion of Int4h through C3 $\left(\Delta G^{\ddagger}=7.0 \mathrm{kcal} / \mathrm{mol}\right)$ gives the $\left(\eta^{2}\right.$-cyclobutene $)$ gold(I) complex Int $7 \mathbf{h} .{ }^{39}$ The alternative ring expansion of cyclopropyl gold(I) carbene Int4h through the terminal alkene carbon C4 generates a distorted (cyclobutene)gold(I) complex Int12h through a low barrier of $5.2 \mathrm{kcal} / \mathrm{mol}$. Interestingly, an intermediate similar to Int $12 \mathrm{~h}$ was not found in the reaction of phenylacetylene derivatives $\mathbf{1 a}$ and $\mathbf{1 e}$ with alkene $\mathbf{2 a}$ discussed above. Intermediate Int $12 h$ undergoes formal 
Scheme 9. Mechanism for the Reaction of the (1-Phenyl-1,3butadiyne)gold(I) Complex with 2-Methylpropene ${ }^{a}$
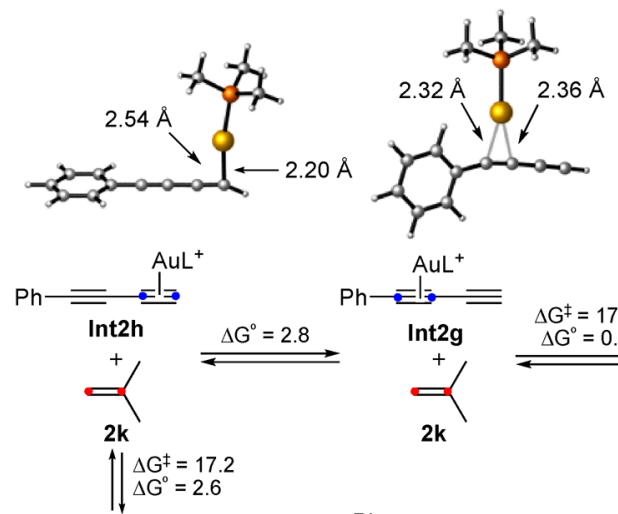

$\mathrm{AuL}^{+}$
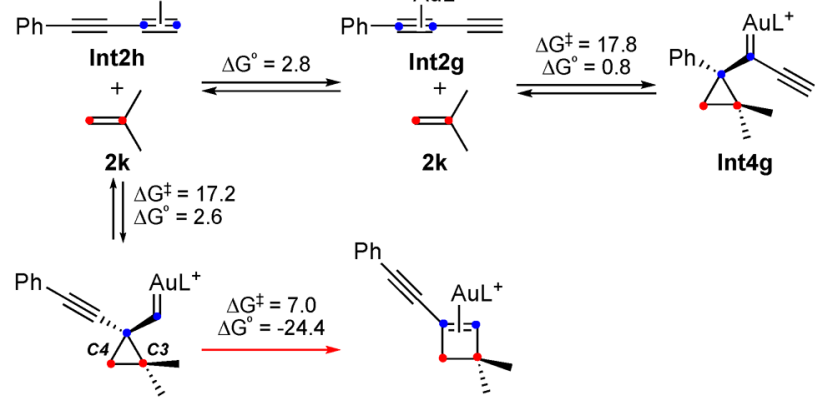

Int4h

Int7h
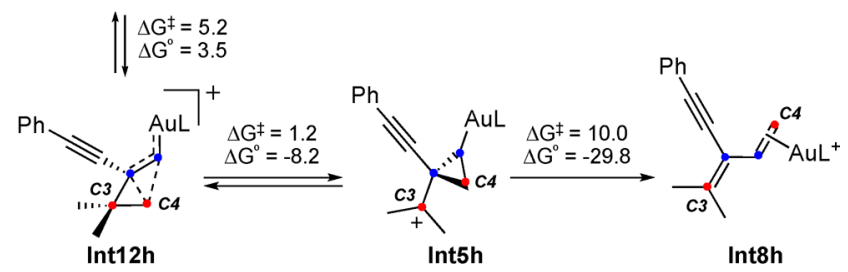

${ }^{a}$ Free energies in $\mathrm{kcal} / \mathrm{mol} . \mathrm{L}=\mathrm{PMe}_{3}$.

insertion of the terminal alkene carbon $\mathrm{C} 4$ into the alkyne carbons to form a more stable cyclopropyl-like intermediate, Int5h. Although intermediates Int4h, Int12h, and Int5h are in equilibrium through low barrier transformations, ring opening of Int5h to form (1,3-diene-gold(I) complex) Int8h is more energetically costly than the expansion of Int4h to $\left(\eta^{2}\right.$ cyclobutene)gold(I) complex Int $7 \mathrm{~h}(10.0 \mathrm{vs} 7.0 \mathrm{kcal} / \mathrm{mol})$, which is fully consistent with the experimental results.

Further Experimental Support for the Involvement of Cyclopropyl Gold(I) Carbenes. We have discovered a method to generate gold(I) carbenes by the retro-Buchner reaction of 7-substituted 1,3,5-cycloheptatrienes with electrophilic gold(I) catalysts, in a process in which a molecule of benzene is also formed in a formal decarbenation reaction. ${ }^{46,47}$ The retro-Buchner reaction proceeds by stepwise cleavage of the norcaradienes, which are in tautomeric equilibrium with the cycloheptatriene. ${ }^{46}$ Other related decarbenations have been observed in the presence of gold(I). ${ }^{48,49}$

When 7-cyclopropylcycloheptatriene $\mathbf{1 4}$ was heated in the presence of catalyst $\mathbf{A},(Z, Z)$-1,4-diphenyl-1,3-diene $[(Z, Z)-15]$ was formed selectively (Scheme 10). ${ }^{46}$ This transformation presumably proceeds via cyclopropyl gold(I) carbene 16a, which undergoes a formal 1,3-shift of a $\mathrm{CHPh}$ fragment. Interestingly, 16a would correspond to the intermediate generated in the gold(I)-catalyzed reaction between acetylene and trans-stilbene. The ring expansion of 16a to form cyclobutene 17 , which would have given diene $(E, E)-15$ by conrotatory opening, ${ }^{50}$ was not observed. ${ }^{46}$ This result predicts that a cis-isomer of 7-cyclopropylcycloheptatriene 14 would give rise to the diene $(E, Z)-15$. Unfortunately, this isomer could not be prepared by the same method used for the synthesis of 14.
Scheme 10. Formation of (Z,Z)-1,4-Diphenylbuta-1,3-diene by Retro-Buchner Reaction of Cycloheptatriene $14^{47}$<smiles>c1ccc(C2C(c3ccccc3)C2c2ccccc2)cc1</smiles>

14

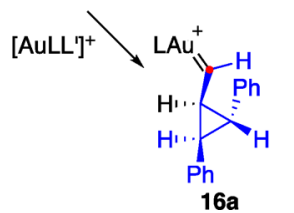

$(Z, Z)-15(59 \%)$

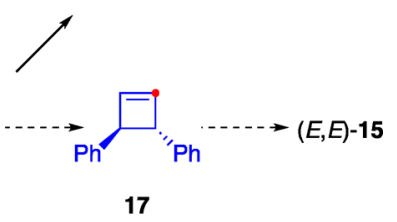

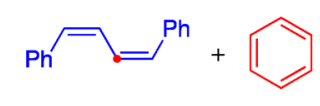

Since the generation of intermediates such as 16 a by a totally different process could be relevant to the better understanding of the mechanism of the gold(I)-catalyzed reaction of alkynes with alkenes, we recurred to our initial system for the generation of gold(I) carbenes by decarbenation of $1 \mathrm{a}, 7 \mathrm{~b}$ dihydro- $1 H$-cyclopropa[a]naphthalenes (Scheme 11). ${ }^{48}$ The

Scheme 11. Retro-Buchner Reactions of $19 a, b^{a}$
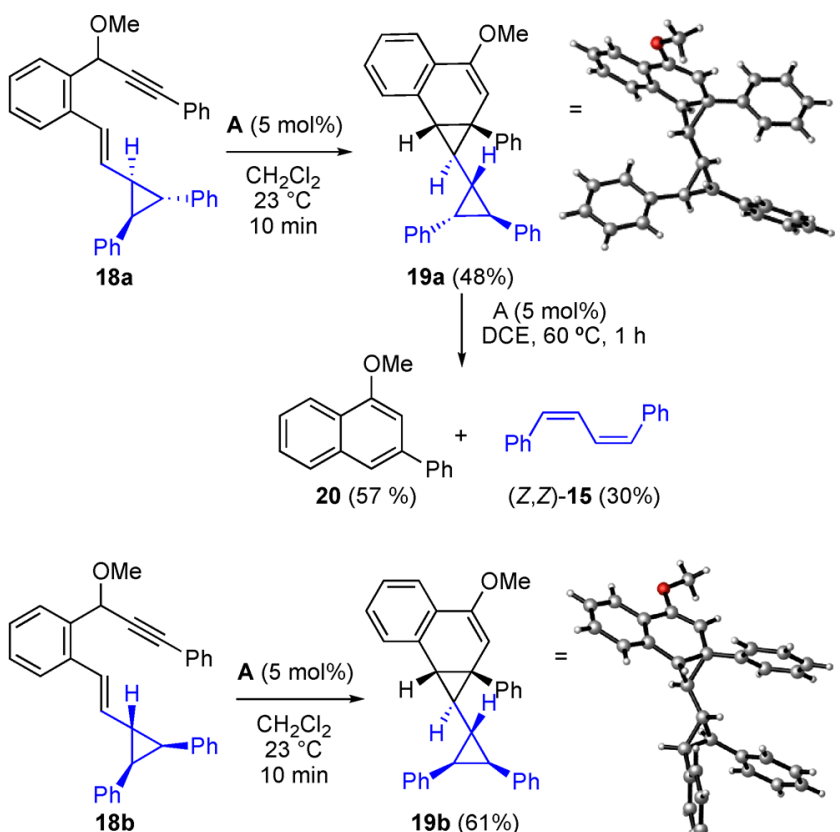

$19 \mathrm{~b}(61 \%)$
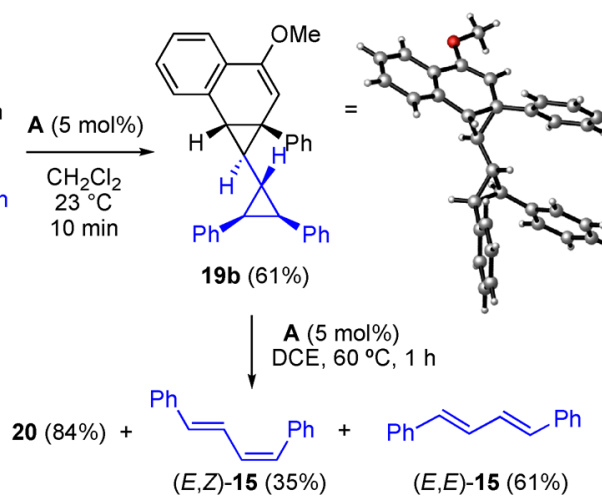

${ }^{a}$ CYLview depiction of the X-ray crystal structures of $19 \mathbf{a}, \mathbf{b}$.

required starting 1,6-enynes $\mathbf{1 8 a}$, b were prepared as a ca. 1:1 mixture of epimers at the benzylic position by olefination of the corresponding cyclopropyl carbaldehydes. ${ }^{51,52}$ The gold(I)catalyzed cycloisomerization of $\mathbf{1 8} \mathbf{a}, \mathbf{b}$ takes place under mild conditions using catalyst A to furnish enol ethers 19a,b in $48 \%$ and $61 \%$ yields, respectively, whose relative configurations were determined by X-ray diffraction. When enol ether 19a was heated with catalyst $\mathrm{A}$ in 1,2-dichloroethane at $60{ }^{\circ} \mathrm{C}$, the decarbenation reaction provided 1-methoxy-3-phenylnaphtha- 
lene $(20)$ and $(Z, Z)-15 .^{53}$ Similarly, substrate $19 \mathrm{~b}$ reacted at 60 ${ }^{\circ} \mathrm{C}$ for $1 \mathrm{~h}$ with catalyst $\mathrm{A}$ to give naphthalene $\mathbf{2 0}$ together with a $1: 2$ mixture of $(E, Z)$ - and $(E, E)-15 .^{54}$

The retro-Buchner (decarbenation) reaction of $19 \mathrm{a}$ should lead to the same cyclopropyl gold(I) carbene 16a (=Int4i) generated from trans-14, whose opening by $C 3$ migration via Int5i leads to Int8i and ultimately to $(Z, Z)-15^{46,55 a}$ (Scheme 12 ). On the other hand, $19 b$ would give rise to intermediate

Scheme 12. Mechanism for the Formation of 1,3-Dienes 15 via Retro-Buchner Reaction from $19 a, b^{a}$

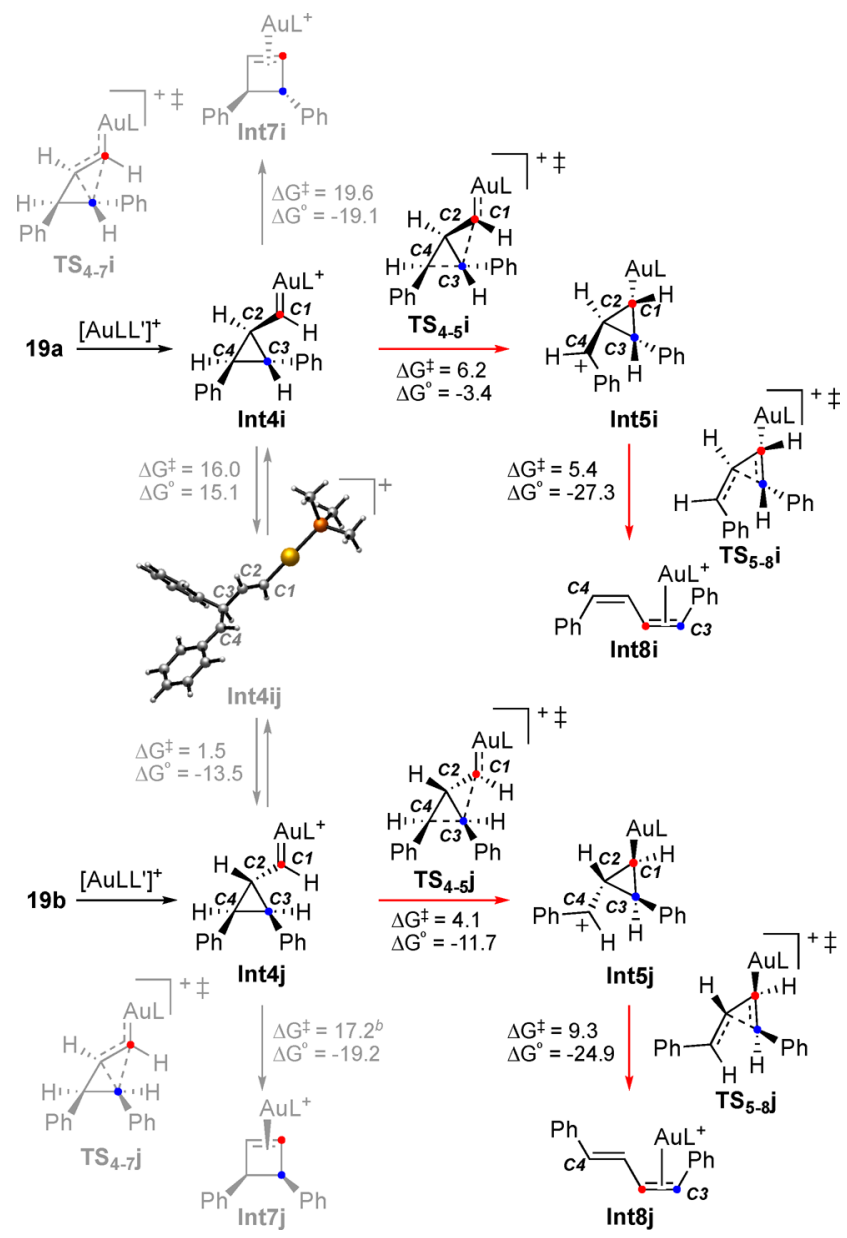

${ }^{a}$ Free energies in $\mathrm{kcal} / \mathrm{mol} . \mathrm{L}=\mathrm{PMe}_{3} .{ }^{b}$ The energy of $\mathbf{T S}_{4-7} \mathbf{j}$ was calculated by freezing the following distances: $d(\mathrm{C} 3-\mathrm{C} 1), d(\mathrm{C} 3-\mathrm{C} 2)$, and $d(\mathrm{C} 3-\mathrm{C} 4)$. The values of these distances were taken from the previously optimized geometry of $\mathbf{T S}_{4-7} \mathbf{i}$.

Int4j, which undergoes opening via Int5j to furnish $(E, Z)-\mathbf{1 5}$, although this 1,3-diene was obtained together with the more stable isomer $(E, E)-15{ }^{55 \mathrm{~b}}$ Control experiments showed that $(E, Z)-15$ undergoes isomerization to give $(E, E)-\mathbf{1 5}$ in the presence of gold(I) under the reaction conditions. ${ }^{52}$ In full agreement with the experiments, DFT calculations show that the alternative expansion of cyclopropyl gold(I) carbenes Int4i,j to cyclobutenes Int7i $\mathbf{i} \mathbf{j}$ is a higher energy process. ${ }^{39}$

Although both reaction pathways from 19a,b could in principle be connected by the trans- to cis-isomerization of Int4i to Int4j via open carbocation Int4ij (Scheme 12), in contrast to that found in the equilibrium between Int4a and Int4b (Scheme 6), here the corresponding barriers are much higher in energy than those leading to $\mathrm{C} 3$ migration. ${ }^{56}$
Finally, it is interesting to compare these results with known examples of formation of cyclobutenes via cyclopropyl carbenes. Thus, the photolysis of cis- and trans-21 has been shown to give cis- and trans-22 cyclobutenes, respectively, as a result of a stereospecific ring expansion (Scheme 13a). ${ }^{57}$ In

Scheme 13. Photochemical ${ }^{58}$ (a), Metal-Catalyzed ${ }^{59}$ (b), and Thermal $^{61}$ (c) Generation and Fate of Cyclopropyl Carbenes a)

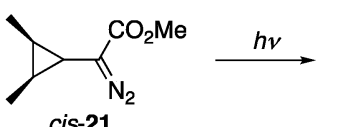

cis-21<smiles>COC(=O)C1C(C)[C@@H]1C</smiles>
trans-21

b)

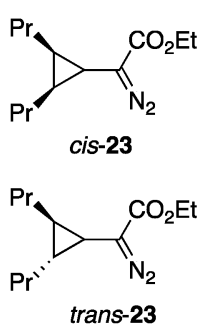

c)

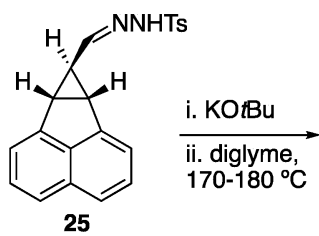

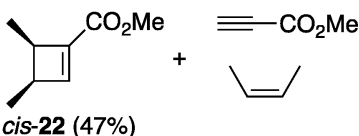

cis-22 (47\%)

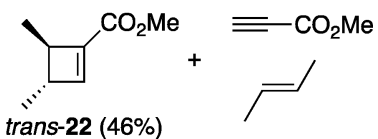

trans-22 (46\%)
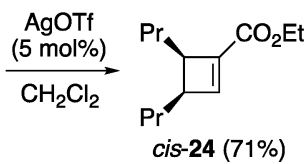

AgOTf

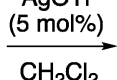

(1)

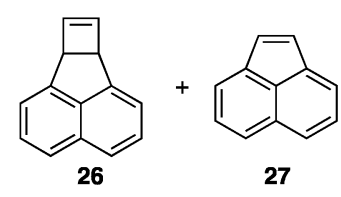

these reactions, methyl propiolate and cis- or trans-2-butene were also obtained as a result of a competitive fragmentation. Likewise, in the presence of AgOTf, cis- and trans-23 undergo stereospecific ring expansion to cyclobutenes cis- and trans-24, respectively (Scheme $13 \mathrm{~b}){ }^{58,59}$ The thermal decomposition of the potassium salt of tosyl hydrazone $\mathbf{2 5}$ also led to a product of ring expansion (26), together with acenaphthylene (27), the product of fragmentation (Scheme 13c). ${ }^{60}$ Ring expansion to cyclobutenes and fragmentation to form alkenes and alkynes have also been observed in reactions of simple cyclopropyl carbenes. $^{57}$

\section{CONCLUSIONS}

Electron-rich alkynes have been shown to react with alkenes in the presence of gold(I) catalysts by $[2+2]$ cycloaddition to give rise to cyclobutenes, whereas, in contrast, electrondeficient alkynes lead to 1,3-dienes in a metathesis-type process. Now we have found that 1,3-dienes can also be obtained in the reaction of alkenes with electron-rich alkynes bearing ortho-substituted aryls.

The two reaction channels leading to cyclobutenes or 1,3dienes are close in energy. According to all our calculations, the first intermediates in the gold(I)-catalyzed intermolecular reaction of alkynes with alkenes are cyclopropyl gold(I) carbenes, which despite all the experimental efforts ${ }^{27,61}$ are still elusive species. To substantiate their involvement in these transformations, we have generated these intermediates by a totally different method based on the gold(I)-promoted retroBuchner reaction, which also leads to the formation 1,3-dienes 
by a metathesis-type mechanism. The formation of 1,3-dienes involves a two- or three-step mechanism in which the carboncarbon double bond of the alkene is cleaved, similar to that proposed in the gold(I)-catalyzed intramolecular skeletal rearrangements of 1,6-enynes. Products of conrotatory opening of cyclobutenes are not observed in the gold(I)-catalyzed reaction of alkynes with alkenes, which is consistent with the high activation energy required for this process.

The common mechanistic scenario for gold(I)-catalyzed reactions of alkynes with alkenes involves the initial formation of cyclopropyl gold(I) carbene intermediates, followed by fast ring expansion or rearrangement. Formation of 1,3-dienes can take place from both electron-rich and electron-deficient alkynes, although cyclobutenes have only been obtained in gold(I)-catalyzed reactions involving electron-rich alkynes. There is another important difference between the reactions of electron-rich and electron-deficient alkynes since in the former case the alkene reacts with the internal carbon of the alkyne, whereas in the second case the alkene attacks the terminal carbon, leading to regioisomeric cyclopropyl gold(I) carbenes.

\section{ASSOCIATED CONTENT}

\section{S Supporting Information}

The Supporting Information is available free of charge on the ACS Publications website at DOI: 10.1021/jacs.7b03005.

All procedures and characterization data for new compounds (PDF)

Full details of the theoretical calculations (PDF)

X-ray crystallographic data for $3 \mathbf{v}$ (CIF)

$\mathrm{X}$-ray crystallographic data for $\mathbf{1 1 w}$ (CIF)

X-ray crystallographic data for 19a (CIF)

X-ray crystallographic data for $19 b$ (CIF)

X-ray crystallographic data for 19c (CIF)

\section{AUTHOR INFORMATION}

\section{Corresponding Authors}

*fmaseras@iciq.es

*aechavarren@iciq.es

\section{ORCID}

Yahui Wang: 0000-0003-4109-8318

Feliu Maseras: 0000-0001-8806-2019

Antonio M. Echavarren: 0000-0001-6808-3007

Notes

The authors declare no competing financial interest.

\section{ACKNOWLEDGMENTS}

We thank the Ministerio de Economía, Industria y Competitividad (MINECO)/Fondo Europeo de Desarrollo Regional (FEDER), Unión Europea (UE) (Grant CTQ2016-75960P), MINECO-Severo Ochoa Excellence Accreditation 20142018, Grant SEV-2013-03 and a Severo Ochoa predoctoral fellowship to M.E.d.O., the European Research Council (Advanced Grant No. 321066), the Agència de Gestió d'Ajuts Universitaris i de Recerca (AGAUR) (Grant 2014 SGR 818), and the Centres de Recerca de Catalunya (CERCA) Program/ Generalitat de Catalunya for financial support. We also thank the ICIQ X-ray diffraction unit for the X-ray structures.

\section{REFERENCES}

(1) (a) Jiménez-Núñez, E.; Echavarren, A. M. Chem. Rev. 2008, 108, 3326-3350. (b) Obradors, C.; Echavarren, A. M. Acc. Chem. Res. 2014, 47, 902-912. (c) Dorel, R.; Echavarren, A. M. Chem. Rev. 2015, 115, $9028-9072$.

(2) (a) Fürstner, A. Chem. Soc. Rev. 2009, 38, 3208-3221. (b) Fürstner, A. Acc. Chem. Res. 2014, 47, 925-938. (c) Zhang, Y.; Luo, T.; Yang, Z. Nat. Prod. Rep. 2014, 31, 489-503. (d) Pflästerer, D.; Hashmi, A. S. K. Chem. Soc. Rev. 2016, 45, 1331-1367. (e) Stathakis, C. I.; Gkizis, P. L.; Zografos, A. L. Nat. Prod. Rep. 2016, 33, 1093-1117.

(3) (a) López-Carrillo, V.; Echavarren, A. M. J. Am. Chem. Soc. 2010, 132, 9292-9294. (b) de Orbe, M. E.; Echavarren, A. M. Org. Synth. 2016, 93, 115-126.

(4) Homs, A.; Obradors, C.; Leboeuf, D.; Echavarren, A. M. Adv. Synth. Catal. 2014, 356, 221-228.

(5) Obradors, C.; Leboeuf, D.; Aydin, J.; Echavarren, A. M. Org. Lett. 2013, 15, 1576-1579.

(6) Ranieri, B.; Obradors, C.; Mato, M.; Echavarren, A. M. Org. Lett. 2016, 18, 1614-1617.

(7) (a) Lee-Ruff, E.; Mladenova, G. Chem. Rev. 2003, 103, 14491484. (b) Namyslo, J. C.; Kaufmann, D. E. Chem. Rev. 2003, 103, 1485-1538. (c) Luparia, M.; Audisio, D.; Maulide, N. Synlett 2011, 2011, 735-740. (d) Misale, A.; Niyomchon, S.; Maulide, N. Acc. Chem. Res. 2016, 49, 2444-2458.

(8) (a) Masarwa, A.; Fürstner, A.; Marek, I. Chem. Commun. 2009, 5760-5762. (b) Liu, R.; Zhang, M.; Wyche, T. P.; WinstonMcPherson, G. N.; Bugni, T. S.; Tang, W. Angew. Chem., Int. Ed. 2012, 51, 7503-7506. (c) Niyomchon, S.; Audisio, D.; Luparia, M.; Maulide, N. Org. Lett. 2013, 15, 2318-2321. (d) Souris, C.; Misale, A.; Chen, Y.; Luparia, M.; Maulide, N. Org. Lett. 2015, 17, 4486-4489. (e) Chen, Y.-J.; Hu, T.-J.; Feng, C.-G.; Lin, G.-Q. Chem. Commun. 2015, 51, 8773-8776. (f) Eisold, M.; Didier, D. Angew. Chem., Int. Ed. 2015, 54, 15884-15887. (g) Guisán-Ceinos, M.; Parra, A.; MartínHeras, V.; Tortosa, M. Angew. Chem., Int. Ed. 2016, 55, 6969-6972. (h) Mercer, J. A. M.; Cohen, C. M.; Shuken, S. R.; Wagner, A. M.; Smith, M. W.; Moss, F. R., III; Smith, M. D.; Vahala, R.; GonzalezMartinez, A.; Boxer, S. G.; Burns, N. Z. J. Am. Chem. Soc. 2016, 138, 15845-15848. (i) Roy, S. R.; Eijsberg, H.; Bruffaerts, J.; Marek, I. Chem. Sci. 2017, 8, 334-339. (j) Eisold, M.; Baumann, A. N.; Kiefl, G. M.; Emmerling, S. T.; Didier, D. Chem. - Eur. J. 2017, 23, 1634-1644.

(9) (a) Yang, C.; Inoue, Y. Chem. Soc. Rev. 2014, 43, 4123-4143. (b) Brimioulle, R.; Lenhart, D.; Maturi, M. M.; Bach, T. Angew. Chem., Int. Ed. 2015, 54, 3872-3890. (c) Xu, Y.; Conner, M. L.; Brown, M. K. Angew. Chem., Int. Ed. 2015, 54, 11918-11928. (d) Blum, T. R.; Miller, Z. D.; Bates, D. M.; Guzei, I. A.; Yoon, T. P. Science 2016, 354, 1391-1395. (e) Tröster, A.; Alonso, R.; Bauer, A.; Bach, T. J. Am. Chem. Soc. 2016, 138, 7808-7811. (f) Poplata, S.; Tröster, A.; Zou, Y.Q.; Bach, T. Chem. Rev. 2016, 116, 9748-9815.

(10) (a) Lautens, M.; Klute, W.; Tam, W. Chem. Rev. 1996, 96, 4992. (b) Xu, Y.; Conner, M. L.; Brown, M. K. Angew. Chem., Int. Ed. 2015, 54, 11918-11928. (c) Fructos, M. R.; Prieto, A. Tetrahedron 2016, 72, 355-369.

(11) (a) The cobalt(I)-catalyzed reaction of 1,3-enynes shows a broader scope, leading to cyclobutenes with a variety of styrenes and other terminal alkenes: Nishimura, A.; Tamai, E.; Ohashi, M.; Ogoshi, S. Chem. - Eur. J. 2014, 20, 6613-6617. (b) Ni(0)-catalyzed reaction of 1,3-enynes to form cyclobutenes: Nishimura, A.; Ohashi, M.; Ogoshi, S. J. Am. Chem. Soc. 2012, 134, 15692-15695.

(12) Sakai, K.; Kochi, T.; Kakiuchi, F. Org. Lett. 2013, 15, 10241027.

(13) Motokura, K.; Nakayama, K.; Miyaji, A.; Baba, T. ChemCatChem 2011, 3, 1419-1421.

(14) (a) Shibata, T.; Takami, K.; Kawachi, A. Org. Lett. 2006, 8, 1343-1345. (b) Kossler, D.; Cramer, N. Chem. Sci. 2017, 8, 18621866.

(15) Tam, W.; Goodreid, J.; Cockburn, N. Curr. Org. Synth. 2009, 6, 219-238. 
(16) (a) Jordan, R. W.; Tam, W. Org. Lett. 2000, 2, 3031-3034. (b) Huang, D.-J.; Rayabarapu, D. K.; Li, L.-P.; Sambaiah, T.; Cheng, C.-H. Chem. - Eur. J. 2000, 6, 3706-3713. (c) Chao, K. C.; Rayabarapu, D. K.; Wang, C.-C.; Cheng, C.-H. J. Org. Chem. 2001, 66, 8804-8810. (d) Alvarez, P.; Gimeno, J.; Lastra, E.; García-Granda, S.; Van der Maelen, J. F.; Bassetti, M. Organometallics 2001, 20, 37623771. (e) Treutwein, J.; Hilt, G. Angew. Chem., Int. Ed. 2008, 47, 6811-6813. (f) Fan, B.-M.; Li, X.-J.; Peng, F.-Z.; Zhang, H.-B.; Chan, A. S. C.; Shao, Z.-H. Org. Lett. 2010, 12, 304-306. (g) Hilt, G.; Paul, A.; Treutwein, J. Org. Lett. 2010, 12, 1536-1539.

(17) (a) Snider, B. B.; Rodini, D. J.; Conn, R. S. E.; Sealfon, S. J. Am. Chem. Soc. 1979, 101, 5283-5293. (b) Snider, B. B. Acc. Chem. Res. 1980, 13, 426-432. (c) Okamoto, K.; Shimbayashi, T.; Tamura, E.; Ohe, K. Org. Lett. 2015, 17, 5843-5845 and references therein.

(18) Inanaga, K.; Takasu, K.; Ihara, M. J. Am. Chem. Soc. 2005, 127, 3668-3669.

(19) Cyclobutenes can also be obtained by the reaction of in situ generated $\mathrm{Tf}_{2} \mathrm{C}=\mathrm{CH}_{2}$ and alkynes: (a) Alcaide, B.; Almendros, P.; Fernández, I.; Lázaro-Milla, C. Chem. Commun. 2015, 51, 3395-3398. (b) Almendros, P.; Alcaide, B.; Lázaro-Milla, C. Adv. Synth. Catal. 2017, DOI: 10.1002 /adsc.201700492.

(20) Yeom, H.-S.; Koo, J.; Park, H.-S.; Wang, Y.; Liang, Y.; Yu, Z.-X.; Shin, S. J. Am. Chem. Soc. 2012, 134, 208-211.

(21) (a) Nieto-Oberhuber, C.; López, S.; Muñoz, M. P.; Cárdenas, D. J.; Buñuel, E.; Nevado, C.; Echavarren, A. M. Angew. Chem., Int. Ed. 2005, 44, 6146-6148. (b) Escribano-Cuesta, A.; Pérez-Galán, P.; Herrero-Gómez, E.; Sekine, M.; Braga, A. A. C.; Maseras, F.; Echavarren, A. M. Org. Biomol. Chem. 2012, 10, 6105-6111.

(22) Harris, R. J.; Widenhoefer, R. A. Chem. Soc. Rev. 2016, 45, $4533-4551$.

(23) Lee, S. I.; Kim, S. M.; Choi, M. R.; Kim, S. Y.; Chung, Y. K.; Han, W.-S.; Kang, S. O. J. Org. Chem. 2006, 71, 9366-9372.

(24) Odabachian, Y.; Gagosz, F. Adv. Synth. Catal. 2009, 351, 379386.

(25) (a) Zhuo, L.-G.; Zhang, J.-J.; Yu, Z.-X. J. Org. Chem. 2012, 77, 8527-8540. (b) Zhuo, L.-G.; Shi, Y.-C.; Yu, Z.-X. Asian J. Org. Chem. 2014, 3, 842-846. (c) Zhuo, L.-G.; Zhang, J.-J.; Yu, Z.-X. J. Org. Chem. 2014, 79, 3809-3820.

(26) (a) Soriano, E.; Ballesteros, P.; Marco-Contelles, J. J. Org. Chem. 2004, 69, 8018-8023. (b) Soriano, E.; Marco-Contelles, J. J. Org. Chem. 2005, 70, 9345-9353. (c) Soriano, E.; Marco-Contelles, J. Acc. Chem. Res. 2009, 42, 1026-1036.

(27) (a) Brooner, R. E. M.; Brown, T. J.; Widenhoefer, R. A. Angew. Chem., Int. Ed. 2013, 52, 6259-6261. (b) Brooner, R. E. M.; Robertson, B. D.; Widenhoefer, R. A. Organometallics 2014, 33, 64666473. (c) Kim, N.; Brooner, R.; Widenhoefer, R. A. Organometallics 2017, 36, 673-678.

(28) All reactions were performed in the presence of an excess of alkene with respect to alkyne (2-4 to 1$)$ because of its partial oligomerization under the reaction conditions and to minimize competitive reaction of the 1,3-dienes with the alkyne, leading to the formation of 2:1 adducts.

(29) In an independent study, the reactions of le and (o-iodophenyl) acetylene with 2,3-dimethyl-2-butene were shown to give only cyclobutenes as products: Hashmi, A. S. K.; Wieteck, M.; Braun, I.; Rudolph, M.; Rominger, F. Angew. Chem., Int. Ed. 2012, 51, 1063310637.

(30) The yield of this $[2+2]$ cycloaddition under these new conditions $\left(5 \mathrm{~mol} \% \operatorname{gold}(\mathrm{I})\right.$-catalyst $\mathbf{A}^{\prime}$, at $50{ }^{\circ} \mathrm{C}$ ) is higher than that previously obtained $\left(3 \mathrm{~mol} \% \mathbf{A}^{\prime}\right.$ at $\left.23{ }^{\circ} \mathrm{C}\right)$. $^{3,4}$

(31) When lower catalyst loadings such as $1 \mathrm{~mol} \%$ were used, longer reaction times were required and in some cases lower yields were obtained. For instance, the reaction of 1e with $2 \mathbf{a}$ in the presence of 1 mol \% catalyst A required 3 days to give a $37 \%$ yield of the 1,3-diene $11 \mathrm{e}$.

(32) Other gold(I)-catalyzed reactions of 1,3-diynes: Asiri, A. M.; Hashmi, A. S. K. Chem. Soc. Rev. 2016, 45, 4471-4503.

(33) Photochemical synthesis of 1-alkynylcyclobutenes from 1,3diynes and alkenes: (a) Lee, T. S.; Lee, S. J.; Shim, S. C. J. Org. Chem.
1990, 55, 4544-4549. (b) Kwon, J. H.; Lee, S. J.; Shim, S. C. Tetrahedron Lett. 1991, 32, 6719-6722. (c) For 1-alkynylcyclobutenes from 1,3-diynes and alkenes by cobalt catalysis, see ref $16 \mathrm{~g}$.

(34) Reaction of different 1,3-diynes with terminal alkenes such as $\alpha$ methylstyrene (2a), methylenecyclopentane (2c), 2-ethyl-1-butene, or 1,1-diphenylethylene gave only traces of the corresponding cyclobutenes.

(35) (a) Calculations were performed with M06/6-31G(d) (C, H, P), LANL2DZ (Br), and $\mathrm{SDD}(\mathrm{Au})$ in $\mathrm{CH}_{2} \mathrm{Cl}_{2}$ (SMD). Full computational details are provided in the Supporting Information. (b) A dataset collection of computational results is available in the ioChem-BD repository and can be accessed via doi:10.19061/iochembd-1-47: Álvarez-Moreno, M.; de Graaf, C.; Lopez, N.; Maseras, F.; Poblet, J. M.; Bo, C. J. Chem. Inf. Model. 2015, 55, 95-103.

(36) For a recent discussion on the coordination of phosphine ligands to gold(I), see: Ciancaleoni, G.; Scafuri, N.; Bistoni, G.; Macchioni, A.; Tarantelli, F.; Zuccaccia, D.; Belpassi, L. Inorg. Chem. 2014, 53, 9907-9916.

(37) (a) Brown, T. J.; Dickens, M. G.; Widenhoefer, R. A. Chem. Commun. 2009, 6451-6453. (b) Brooner, R. E. M.; Widenhoefer, R. A. Angew. Chem., Int. Ed. 2013, 52, 11714-11724.

(38) (a) Bond rotations in cyclopropyl gold(I) carbenes in cycloisomerizations of 1,6-enynes: Jiménez-Núñez, E.; Claverie, C. K.; Bour, C.; Cárdenas, D. J.; Echavarren, A. M. Angew. Chem., Int. Ed. 2008, 47, 7892-7895. (b) This provides a theoretical rationale to the previously observed lack of diasteroselectivity in the reaction of $\mathbf{1 a}$ with $2 \mathrm{a}-d_{1}{ }^{3 a}$

(39) See the Supporting Information for the full scheme and additional details of the key transition states.

(40) See the Supporting Information for alternative reaction pathways not involving the formation of cyclopropyl gold(I) carbenes.

(41) Gold(I) does not have any influence in the conrotatory opening of a trans-1,3,4-trisubstituted cyclobutene, which occurred by heating at $110{ }^{\circ} \mathrm{C}^{20}$

(42) The gold(I)-catalyzed reaction of benzyl 2-cyclopropyl-2diazoacetate gives the corresponding cyclobutene in high yield, presumably by ring expansion of a cyclopropyl gold(I) carbene: Xu, G.; Zhu, C.; Gu, W.; Li, J.; Sun, J. Angew. Chem., Int. Ed. 2015, 54, 883-887.

(43) Brown, T. J.; Sugie, A.; Leed, M. G. D.; Widenhoefer, R. A. Chem. - Eur. J. 2012, 18, 6959-6971.

(44) Brown, T. J.; Widenhoefer, R. A. J. Organomet. Chem. 2011, 696, $1216-1220$

(45) (a) Brown, T. J.; Dickens, M. G.; Widenhoefer, R. A. J. Am. Chem. Soc. 2009, 131, 6350-6351. (b) Brooner, R. E. M.; Brown, T. J.; Widenhoefer, R. A. Chem. - Eur. J. 2013, 19, 8276-8284.

(46) Solorio-Alvarado, C. R.; Wang, Y.; Echavarren, A. M. J. Am. Chem. Soc. 2011, 133, 11952-11955.

(47) (a) Wang, Y.; Muratore, M. E.; Rong, Z.; Echavarren, A. M. Angew. Chem., Int. Ed. 2014, 53, 14022-14026. (b) Wang, Y.; Herlé, B.; McGonigal, P. R.; Besora, M.; Echavarren, A. M. J. Am. Chem. Soc. 2014, 136, 801-809.

(48) Solorio-Alvarado, C. R.; Echavarren, A. M. J. Am. Chem. Soc. 2010, 132, 11881-11883.

(49) (a) Batiste, L.; Fedorov, A.; Chen, P. Chem. Commun. 2010, 46, 3899-3901. (b) Fedorov, A.; Batiste, L.; Bach, A.; Birney, D. M.; Chen, P. J. Am. Chem. Soc. 2011, 133, 12162-12171.

(50) (a) Wilcox, C. F.; Carpenter, B. K. J. Am. Chem. Soc. 1979, 101, 3897-3905. (b) Boon, B. A.; Green, A. G.; Liu, P.; Houk, K. N.; Merlic, C. A. J. Org. Chem. 2017, 82, 4613-4624.

(51) (a) trans-Isomer: Komendantov, M. I.; Fomina, T. B.; Kuzina, N. A.; Domnin, I. N. J. Org. Chem. USSR (Eng. Trans.) 1974, 10, 219221. (b) Castellino, A. J.; Bruice, T. C. J. Am. Chem. Soc. 1988, 110, $7512-7519$.

(52) See the Supporting Information for details and additional results.

(53) A significant amount of the ketone (not shown), resulting from cleavage of the enol ether of $19 a$, was also obtained. ${ }^{54}$ 
(54) Similar results were obtained from substrate 19c, prepared from an enyne analogous to $\mathbf{1 8 b}$ but with a $p$-tolyl group at the alkyne. ${ }^{54}$

(55) (a) The bond rotation of $\mathrm{C} 2-\mathrm{C} 4$ in Int5i to generate Int5k, which would lead to $(E, Z)-15$, requires a high barrier of $14.8 \mathrm{kcal} /$ $\mathrm{mol}^{42}$ (b) The bond rotation of $\mathrm{C} 2-\mathrm{C} 4$ in Int5j to generate Int5L, which would lead to $(Z, Z)-15$, requires a high barrier of $20.8 \mathrm{kcal} /$ $\mathrm{mol}^{42}$

(56) Similarly, rotational barriers around the C2-C4 bond in Int5i,j are higher $(14.8$ and $20.8 \mathrm{kcal} / \mathrm{mol}$, respectively) than those required to form Int8i,j.

(57) Gallucci, R. R.; Jones, M. J. Am. Chem. Soc. 1976, 98, 77047711.

(58) Xu, H.; Zhang, W.; Shu, D.; Werness, J. B.; Tang, W. Angew. Chem., Int. Ed. 2008, 47, 8933-8936.

(59) Cyclopropyl carbenes generated by Brook rearrangement have also been found to give cyclobutenes: Zhang, F.-G.; Marek, I. J. Am. Chem. Soc. 2017, 139, 8364-8370.

(60) Meinwald, J.; Samuelson, G. E.; Ikeda, M. J. Am. Chem. Soc. 1970, 92, 7604-7606.

(61) Harris, R. J.; Widenhoefer, R. A. Chem. Soc. Rev. 2016, 45, $4533-4551$. 